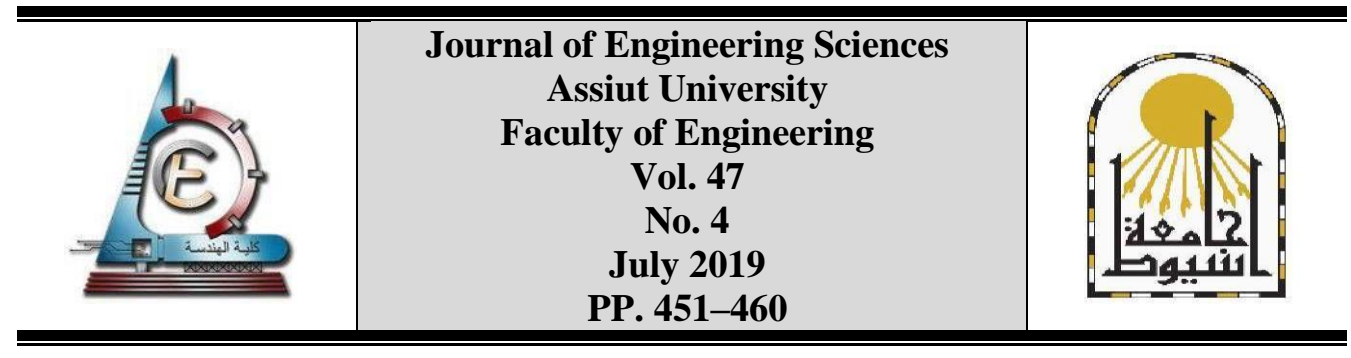

\title{
COMPACTION-INDUCED STRESS IN GEOSYNTHETIC REINFORCED SOIL WALLS
}

\author{
Moamen E. Abd El Raouf \\ Civil Engineering Department, Faculty of Engineering, Al-Azhar University, Egypt
}

Received 25 February 2019; Accepted 4 March 2019

\begin{abstract}
Compaction equipment worked behind the retaining walls causes additional lateral earth pressures acting on the wall. The effect of compaction-induced stress (CIS) usually neglected when designing the retaining walls. Geosynthetic-Reinforced Soil walls (GRS walls) have increasing popularity in Egypt in the last years. The earth pressure at the facing of a Geosynthetic Reinforced Soil wall (GRS wall) is different from that in the natural soil. The internal lateral pressure in the GRS soil is governed by compaction-induced stresses (CIS) and additional confining effects that the reinforcement provides to the soil. The compaction-induced stress for GRS wall is difficult to be predicted during the design stage because it depends on the characteristics of compaction equipment and other factors. The objectives of the research are:1) Studying the effect of compact the backfill of GRS wall by vibratory plates on the internal stability, the external stability, and the foundation soil for GRS wall. 2) Evaluating the performance of the various types of vibratory plates which used to compact the backfill for GRS wall. So, a finite element analysis using GEO5 program was used to achieve these objectives. Finally, the recommendations for the design and construction of GRS walls were highlighted.
\end{abstract}

Keywords: Geosynthetic-Reinforced Soil, compaction-induced stresses, Vibratory plates, and compaction.

\section{Introduction}

Geosynthetic-Reinforced Soil (GRS) structures, like retaining walls, and slopes, have extended increasing popularity in Egypt in the last years. GRS structures have a many uses and benefit. GRS structures are generally more flexible (hence have more resistance to seismic loading and differential settlement), more adaptable to low-permeability backfill, easier to construct, require less over-excavation, and more economical than conventional earth structures [1,2]. Mechanically stabilizes earth walls (or GRS walls) are one of the most important applications types of Geosynthetic-Reinforced Soil structures. The components of GRS walls are a facing unit, a reinforcing unit, and the backfill. Figure (1) shows a typical cross-section of mechanically stabilizes earth wall with modular block facing.

The compaction equipment which worked behind the retaining walls causes additional lateral earth pressures acting on the wall. The Compaction -Induced stress (CIS) depends on 1) the closer the compaction equipment operates to the wall, 2) the weight of the compaction equipment $\left.\left(\mathrm{P}_{\mathrm{s}}\right), 3\right)$ Centrifugal force $\left(\mathrm{P}_{\mathrm{c}}\right)$ or dynamic force due to vibration of the compaction equipment. 4) The dimension of the area of the roller or plate contacting 
the soil. The effect of the residual lateral earth pressure due to compaction usually neglected during the design of the GRS wall.

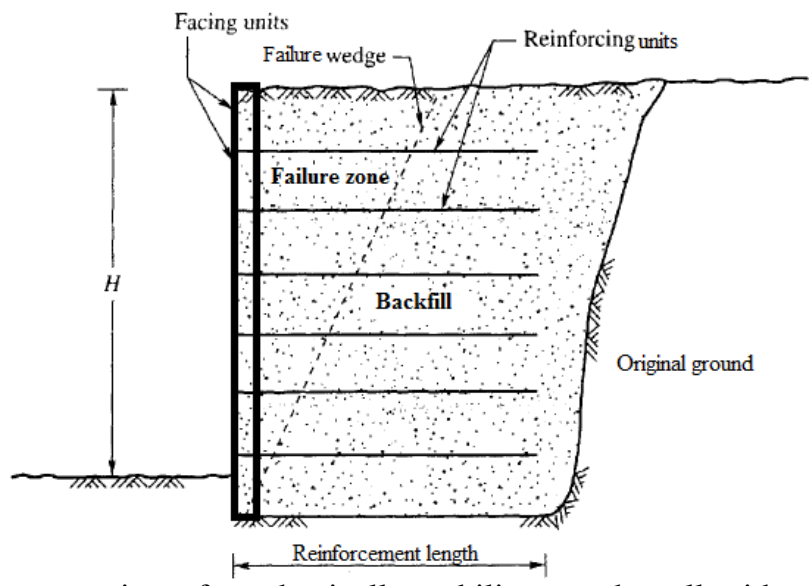

Fig. 1. Typical cross-section of mechanically stabilizes earth wall with modular block facing (after Bowles, J.E., 1988)

The earth pressure at the facing of a Geosynthetic Reinforced Soil wall (GRS wall) is different from that in the unreinforced soil. The internal lateral pressure in the GRS soil is governed by compaction-induced stresses (CIS) and additional confining effects that the reinforcement provides to the soil.

The Compaction -Induced stress (CIS) in GRS is higher than (CIS) in the same unreinforced soil because the reinforcement-soil-interface friction limits soil movement so producing larger values of soil confining stress, and therefore producing a greater CIS than unreinforced soil [3].Increasing the lateral pressure due to compaction on GRS walls will increase the resistance of the reinforced soil as a result of increased friction between the soil and the elements of reinforcement. However, the only drawback, in this case, is that the residual lateral pressure resulting from the compaction is difficult to be predicted during the design stage because the compaction-induced stress depends on the characteristics of compaction equipment. So, it's very important to study the effect of the types of compaction equipment on CIS. Estimated the compaction-induced stresses in GRS wall are considered an important issue in the study of the stability of GRS wall.

The objectives of the research are:

1- Studying the effect of compact the backfill of GRS wall by vibratory plates on the internal stability, the external stability, and the foundation soil for GRS wall.

2- Evaluating the performance of the various types of vibratory plates which used to compact the backfill for GRS wall.

So, a finite element analysis was used to achieve these objectives.

\section{Estimate the compaction-induced stress}

Many researchers developed various methods to estimate the residual lateral earth pressure for unreinforced soil due to compaction [4-5-6-7-8-9].

Duncan and Seed [10] developed charts to estimate the compaction-induced stress on a nonyielding wall by Rollers, Vibratory plates, and Rammers. Figure (2) shows a chart for estimate the compaction -induced stress due to vibratory plate compactors according to Duncan and Seed. 


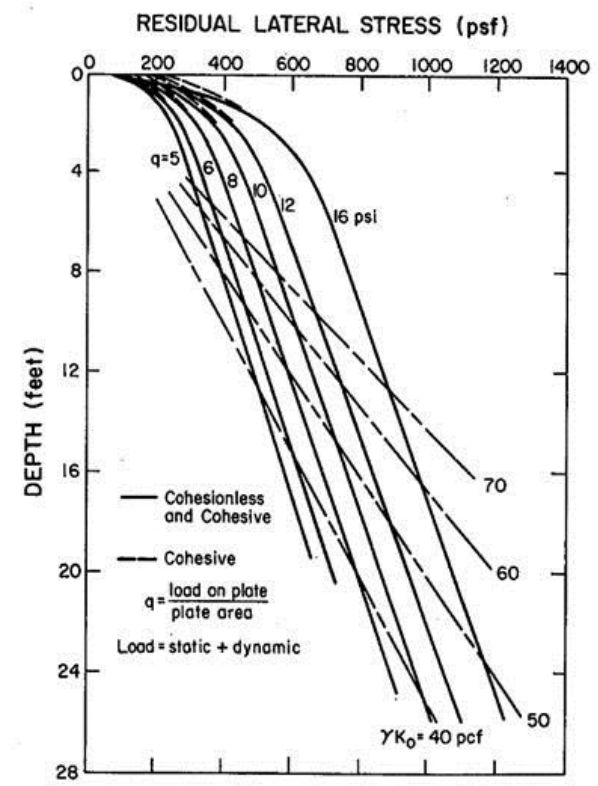

Fig. 2. Compaction-induced stress due to compaction by vibratory plates (after Duncan and Seed,1992)

The compaction -induced stress also can be calculated by the theory of elasticity, where compaction equipment can be represented as a line load (P) $[4,11]$.

The total plate load $(\mathrm{P})$ can be calculated as the following:

$\mathrm{P}=\left(\mathrm{P}_{\mathrm{s}}+\mathrm{P}_{\mathrm{c}}\right) / \mathrm{L}$

Where:

$\mathrm{P}=$ Line load $\mathrm{kN} / \mathrm{m}$

$\mathrm{P}_{\mathrm{s}}=$ Static own weight of the compaction equipment

$\mathrm{P}_{\mathrm{c}}=$ Dynamic force resulting from the centrifugal force

$\mathrm{L}=\mathrm{Width}$ of the vibratory roller or plate.

The behavior and the compaction-induced stress for GRS were studied by many researchers like $[3,12,13,14,15,16,17,18$, and 19].

\section{Compaction equipment}

Later there are several types of compaction equipment. The vibratory compactors are the most popular compaction equipment; it can be classified into two classes; rollers and plates. Plates usually used to compact the GRS walls backfill whether the backfill is sand or gravel. The vibratory plates are working by fuel resulting in movement one or two eccentric weights at a high speed to develop compaction force. Plate's compactor can be classified into two classes; Single Direction and Reversible plates. The reversible vibratory plates permit to directional changes at constant speed.

A survey was done to the most common vibratory plates in Egypt and most parts of the world. The result was as follow: Bomag, NTC, Dynapac, and Masalta are the most common vibratory plates in Egypt and most parts of the world. So, the latest models of these products were studied [20-21-22-23]. Figure (3) shows some types for this 
equipment. Data about vibratory plates were collected which include:

1) The model.

2) The static weight $\left(P_{s}\right)$.

3) Centrifugal force $\left(\mathrm{P}_{\mathrm{c}}\right)$ (the dynamic force)

4) The plate width (L): the dimension of the area of the plate compactor which touches the soil. The data of vibratory plates were collected and tabulated in table (1)

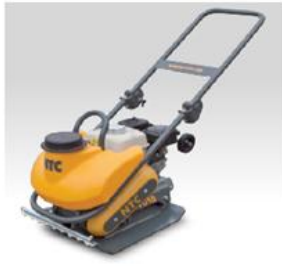

NTC (VD18) Vibratory Plate

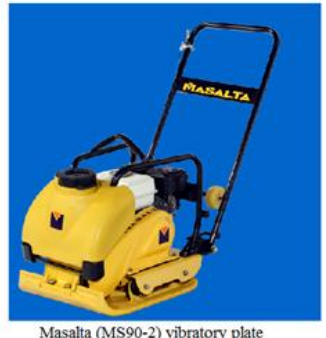

Masalta (MS90-2) vibratory plate

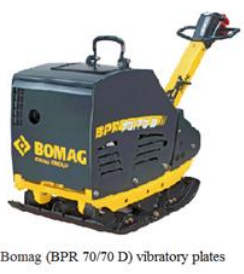

Bomag (BPR 70/70 D) vibratory plates

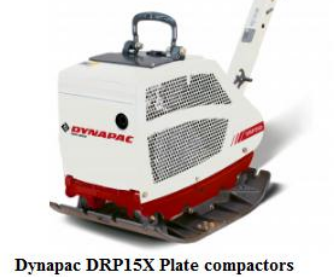

Fig. from (3) The most common vibratory plates

Table 1.

Data of the vibratory plates

\begin{tabular}{|c|c|c|c|c|c|}
\hline No. & Manufacturer & Model & $\begin{array}{l}\text { Static weight } \\
(\text { Ps }) \mathrm{kN}\end{array}$ & $\begin{array}{c}\text { Centrifugal } \\
\text { force } \\
\left(\mathbf{P}_{\mathrm{c}}\right) \mathrm{kN}\end{array}$ & $\begin{array}{l}\text { Plate } \\
\text { width } \\
\text { (L)mm }\end{array}$ \\
\hline 1 & Dynapac & DFP12D & 1.23 & 25 & 500 \\
\hline 2 & Dynapac & DRP15X & 1.4 & 25 & 500 \\
\hline 3 & Dynapac & DFP11 & 1.08 & 25 & 500 \\
\hline 4 & Dynapac & DRP25D & 2.6 & 40 & 600 \\
\hline 5 & Dynapac & DRP70D & 7.05 & 100 & 500 \\
\hline 6 & NTC & VD $15 \mathrm{E}$ & 0.75 & 15 & 400 \\
\hline 7 & NTC & VD 350/16 & 1.05 & 16 & 350 \\
\hline 8 & NTC & VD 24 & 1.15 & 24 & 500 \\
\hline 9 & NTC & VDR 22 & 1.2 & 22 & 400 \\
\hline 10 & NTC & VDR $63 \mathrm{H}$ & 4.4 & 63 & 700 \\
\hline 11 & Bomag & BP 20/50 & 0.95 & 20 & 500 \\
\hline 12 & Bomag & BVP 18/45 & 0.9 & 18 & 360 \\
\hline 13 & Bomag & BPR 35/60 D & 2.22 & 36 & 600 \\
\hline 14 & Bomag & BPR 35/42 D & 2.07 & 35 & 420 \\
\hline 15 & Bomag & BPR 50/55 D & 3.95 & 50 & 550 \\
\hline 16 & Bomag & BPR 70/70 D & 5.7 & 70 & 700 \\
\hline 17 & Bomag & BPR 100/80 D & 7.05 & 100 & 800 \\
\hline 18 & Masalta & MS50-2 & 0.54 & 8.2 & 430 \\
\hline 19 & Masalta & MS60-2 & 0.62 & 10.5 & 500 \\
\hline 20 & Masalta & MS90-2 & 0.83 & 13 & 530 \\
\hline 21 & Masalta & MS100-2 & 0.93 & 19.8 & 460 \\
\hline
\end{tabular}

\section{Numerical modeling}

The finite element program Geo5-2018 was used in this research to estimate the compaction-induced stress in GRS walls. A GEO5 program is a group of software, providing a solution for the majority of geotechnical problems. The stresses which include: the stress on foundation soil and tensile force in geo-reinforcement are measured by the 
finite element program (Geo5-2018) for GRS wall without the effect of the compaction, then the stress on foundation soil and tensile force in geo-reinforcement are measured to the same GRS wall with the effect of the compaction by the vibratory plates. Therefore, any difference in stress on foundation soil or tensile force in geo-reinforcement between the two cases is a result of the effect of the compaction by the vibratory plates.

\subsection{Finite element model data}

The internal stability, external stability, and stress on foundation soil for GRS wall with modular block facing connected to geogrids were studied by finite element program.

The characteristics of the GRS wall in this analysis were as follows:

Geogrid: The reinforcement type is Tensar160RE, and the vertical spacing $(\mathrm{Sv})=0.25 \mathrm{~m}$.

Backfill: sand, the coefficient of direct slip along reinforcement $=0.85$, and the coefficient of the interaction of soil and geo-reinforcement $=0.85$.

Original soil: sand with a unit weight $=19 \mathrm{kN} / \mathrm{m}^{3}$, cohesion $(\mathrm{c})=0$, and friction angle $(\phi)=30$ degree.

Facing units: Modular blocks facing with a unit weight $=23 \mathrm{kN} / \mathrm{m}^{3}$, width $(\mathrm{b})=(0.5$ $\mathrm{m})$, and height $=0.25 \mathrm{~m}$. as shown in figure (4).

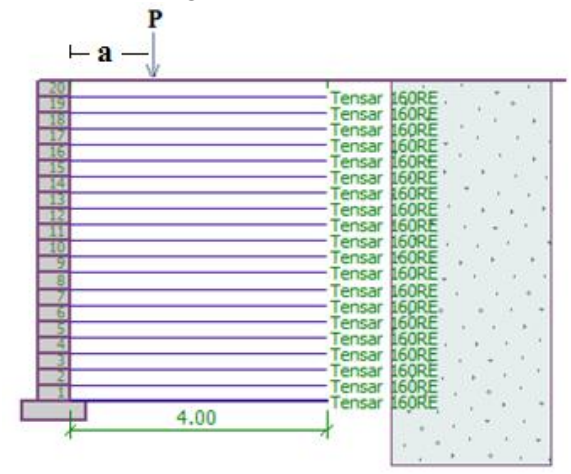

Fig. 4. The finite element model

Where: $\mathrm{a}=$ The distance between the plate compactor and the wall facing

\section{Results of finite element analysis}

The results of Geo5 program was as follow:

\subsection{Stresses on foundation soil}

1- When the plate compactor work directly fronts to the wall facing $(a=0)$ the distribution of stress on foundation soil take trapezoidal shape, the maximum stress at the front of the GRS wall (next to the facing units) and the minimum stress at the backward of the reinforced soil mass. The compaction by plate compactor increases the stress on the foundation soil at the front of the GRS wall. This increase ranges from $11 \%$ to $113 \%$ according to the type of plate compactor as shown in figure (5). The compaction by plate compactor also decreases the stress on foundation soil at the backward of the GRS wall. This decrease ranges from $4 \%$ to $47 \%$ according to the type of plate compactor as shown in figure (6). 
2- As the plate compactor moves away from the facing units (after the failure zone), the distribution of the stress on the foundation soil be more uniform. Figure (7) show the CIS distribution on foundation soil.

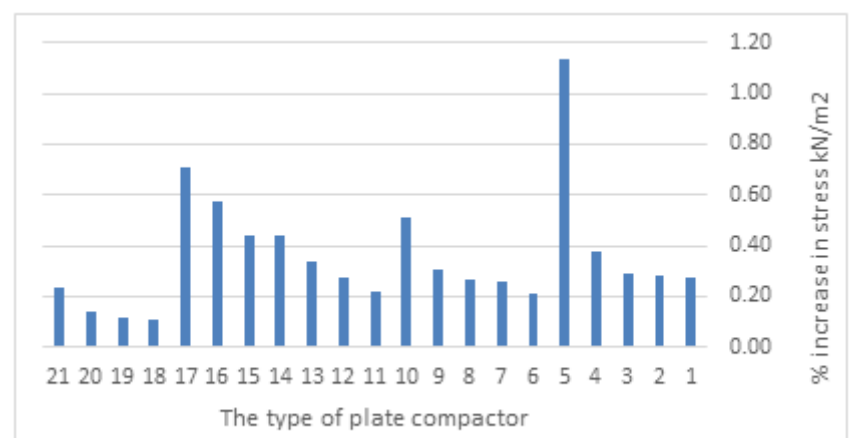

Fig. 5. The relation between the type of vibratory plates and the increase of stress on foundation soil due to compaction at the front of the GRS wall

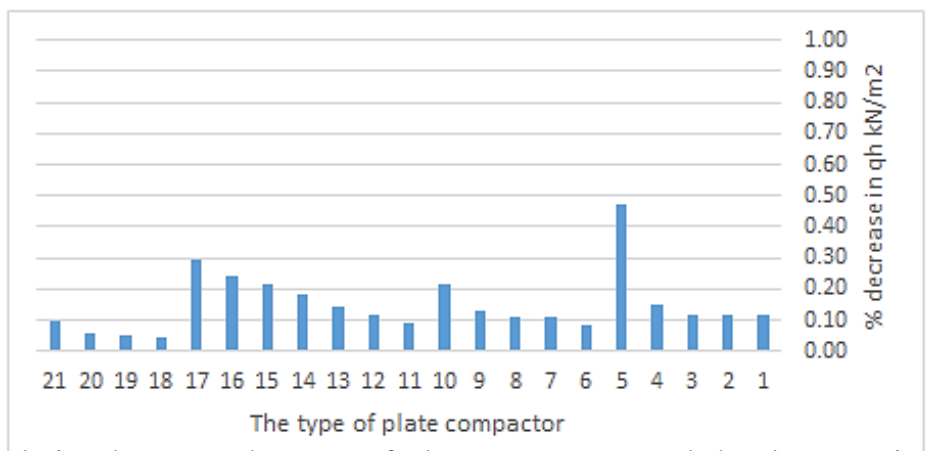

Fig. 6. The relation between the type of plate compactor and the decrease in the stress on the foundation soil due to compaction at the backward of the GRS wall
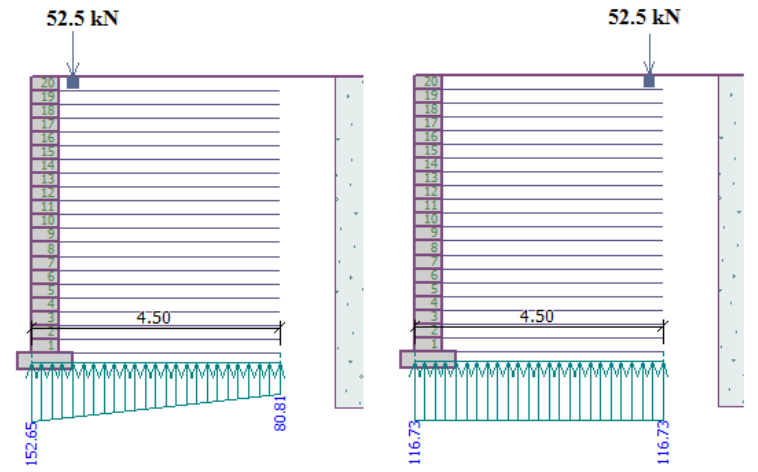

Fig. 7. CIS distribution on foundation soil

\subsection{Effect of CIS on internal stability for GRS wall (forces in geo-reinforcements)}

a- When $a=0$, the tensile force in the geogrid layer increases without the rest of the layers below it as shown in figure (8). At this case the compaction - induced stress transmits to the geogrid layer just below them without the rest of the layers and the total stress may reach to limit that may be unsafe for this geogrid layer.

That means when $a=0$ every layer work independently from the layer which above and below it, according to that the residual lateral earth pressure distribution due to compaction can be expressed as shown in figure (9). 


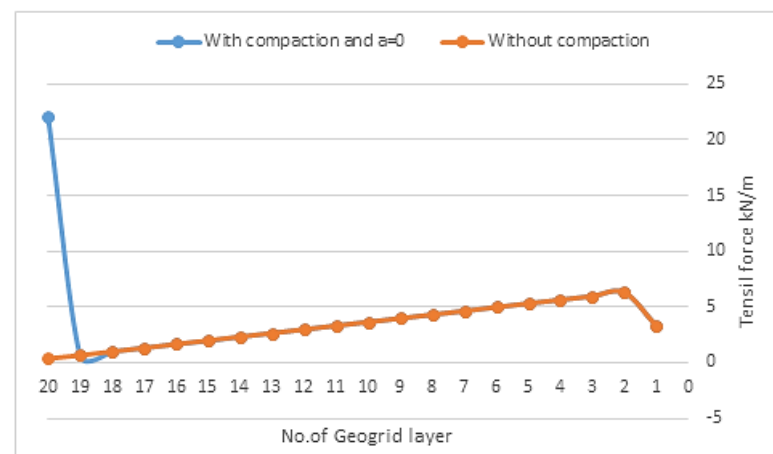

Fig. 8. The tensile force in geo-reinforcement when $a=0 \mathrm{~m}$
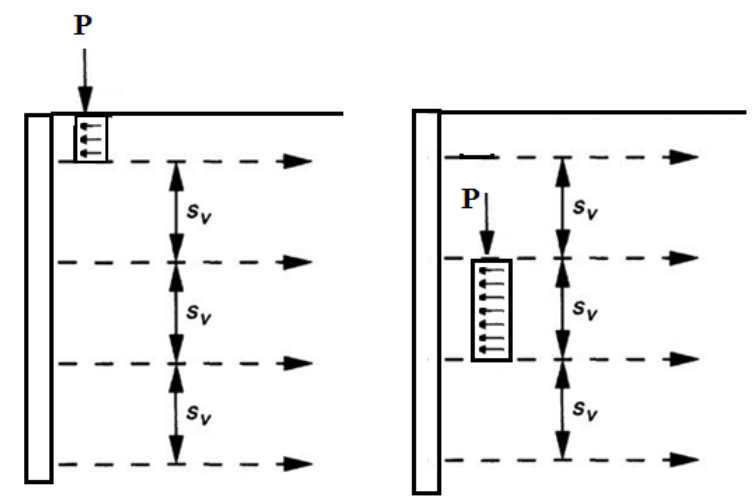

Fig. 9. The stress distribution in geo-reinforcement When $a=0$

b-As the plate compactor moves away from the facing units, the CIS is distributed on the rest geogrid layers below as shown in figure (10). The effect of the CIS reaches nearly to a depth corresponding to half the distance between the plate compactor and the face of the wall $(\mathrm{a} / 2)$.

c-The increase in tensile force in geo-reinforcement due to compaction may be reduced when the next layer is placed and compacted. When backfilling is finish, the compaction-induced stress acts only on the upper geogrid layers.

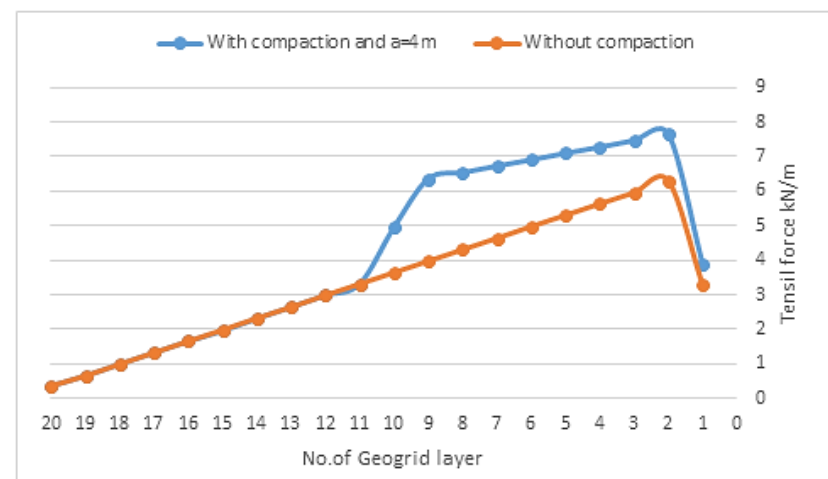

Fig. 10. The tensile force in geo-reinforcement When $a=4 \mathrm{~m}$

\subsection{Effect of CIS on external stability for GRS wall}

a- The compaction-induced stress results in an increase the external stability for the GRS wall which includes stability against overturning and stability against sliding as shown in figures $(11,12)$. 


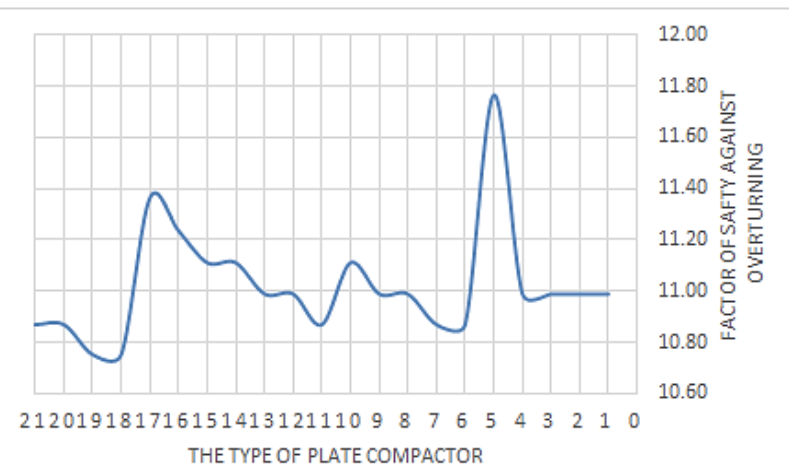

Fig. 11. The relation between the factor of safety against overturning and the type of plate compactor

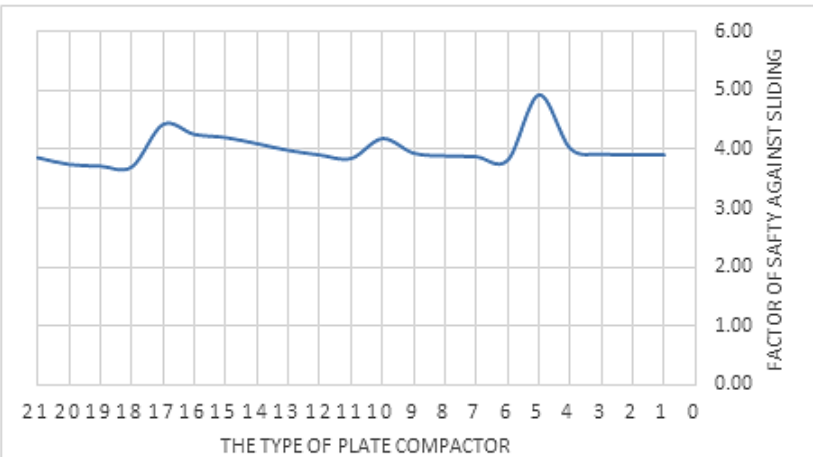

Fig. 12. The relation between the factor of safety against sliding and the type of plate compactor

\section{Optimization and value engineering}

The compaction of backfill for GRS walls increases the resistance of the reinforced soil as a result of increased friction between the soil and the elements of reinforcement (the coefficient of the interaction of soil and geo-reinforcement). Where compaction-induced stress is unknown during the design stage because it depends on the characteristics of compaction equipment. So, the designer can give a recommendation for the type of equipment that must be used in the compaction process, so that the compaction increases the friction between the backfill and the geo-reinforcement and at the same time does not cause a significant increase in lateral earth pressure. This can be achieved by using the plate compactor which has a low centrifugal force (not exceed than $3 \mathrm{kN}$ ) and low static weight (not exceed than $50 \mathrm{kN}$ ). This will also reduce the total cost of compaction.

\section{Conclusions and recommendations}

To avoid excessive additional lateral earth pressures due to compaction, which may cause unacceptable movements to the GRS wall, the engineers should take these precautions into consideration.

1- The critical zone to the effect of the residual earth pressure due to compaction on both internal stability and stress on foundation soil for GRS wall is the area next to the facing units.so it's recommended to avoid using a heavy plate compactor to compact this area. a heavy plate compactor can be used after the failure zone.

2-The factors of safety of tensile strength for geogrid must include a factor of safety to resist the increase of stress due to compaction.

3- It is not advisable to use a plate's compactor with a small width (less than $420 \mathrm{~mm}$ ). 
4-The designer must be taking the effect of the increase of the resistance of the reinforced soil as a result of increased friction between the backfill and the georeinforcement due to compaction into consideration, but in this case, the designer must give recommendations about the type and characteristics of equipment that must be used in the compaction process.

\section{REFERENCES}

[1] Holtz, R.D., Christopher, B.R., and Berg, R. (1997), "Geosynthetic Engineering”, BiTech Publishers, Ltd., Richmond, BC.

[2] Bathurst R.J., Cai, Z., Alfaro, M., and Pelletier, M. (1997). "Seismic Design Issues for Geosynthetic Reinforced Segmental Retaining Walls," Proceedings of the International Symposium on Mechanically Stabilized Backfill, J.T.H. Wu (Ed.), Balkema, Rotterdam, Netherlands.

[3] Thang Quyet Pham, (2009). "Investigating Composite Behavior of Geosynthetic-Reinforced Soil (GRS) Mass Ph.D. Thesis, University of Colorado Denver.

[4] Craig, R. F. (1997), Soil Mechanics, Spon Press, $6^{\text {th }}$. Ed.

[5] Bowles, J.E. (1988), Foundation Analysis \&Design, 5th Edition, McGraw Hill, Sydney.

[6] Tsang-Jiang Chen and Yung-Show Fang, M.ASCE, (2008), "Earth Pressure due to Vibratory Compaction" , Journal of Geotechnical and Geo-environmental Engineering, ASCE,Vol. 134, No. 4, (437).

[7] Broms, B. B. (1971). "Lateral earth pressures due to compaction of cohesionless soils." Proc. 4th Budapest Conference on Soil Mech. and Found. Engrg, 373-384.

[8] Duncan, J. M., and Seed, R. B. (1986). "Compaction-induced earth pressures under $\mathrm{K}_{\mathrm{o}}$ conditions." J- Geotech. Engrg. ASCE, 112(1).

[9] Peck, R. B., and Mesri, G. (1987). Discussion of "Soil-Structure Interaction Effects of Compaction-Induced Stresses and Deflections," J. Geot. Engrg., ASCE.

[10] Duncan, J.M., Williams G..W., Sehn A.L., and Seed, R.B. "Estimation Earth Pressure Due to Compaction". Journal of Geotechnical Engineering, ASCE, 1992, 117, No. 12, pp. 1833-1847.

[11] I. CHMIELEWSKA, M. WYSOCKA, (2012), "Pressure on Retaining Walls from Compaction Effort". Architecture civil engineering environment journal, the Silesian University of Technology, Vol. 5, No. 4, (55-60).

[12] Ketchart, K., and Wu, J. T. H.,(2001) " Performance Test for Geosynthetic Reinforced Soil Including Effects of Preloading", FHWA-RD-01-018, Federal Highway Administration, Washington, DC.

[13]Ketchart, K. (2000). "Behavior of Preloaded Geosynthetic-Reinforced Soil Mass." PhD. Thesis, University of Colorado at Denver, 347 pages.

[14] Wu, J.T.H. (1989), "Behavior of Soil-Geotextile Composites and Its Application to Finite Element Analysis," Proc. of Geosynthetics' 89, 365-372.

[15] Lee, W. F. (2000). "Internal Stability Analyses of Geosynthetic Reinforced Retaining Walls." Ph.D. Thesis, Dept. of Civil and Environmental Engineering, University of Washington, 379 pages.

[16] Abu-Hejleh, N.M., Zornberg, J.G., Elias, V., and Watcharamonthein, J.,(2003) Design Assessment of the Founders/Meadows GRS Abutment Structure, Paper No. 03-3268, Transportation Research Board CD ROM.

[17] Mitchell, J.W.(2002), Behavior of Geosynthetically Reinforced Soil Bridge Piers, M.S. Report,University of Massachusetts at Amherst.

[18] Wu, J.T.H., "Lateral Earth Pressure Against the Facing of Segmental GRS Walls, (2007)"Proceedings, Geosynthetics in Reinforcement and Hydraulic Application, GeoDenver2007: New Peaks in Geotechnics, American Society of Civil Engineers, pp. 1-11.

[19] Adams, M., Nicks, J., Stabile, T., Wu, J., Schlatter, W., and Hartmann, J. (2012). Geosynthetic Reinforced Soil Integrated Bridge System Interim Implementation Guide, Report No. FHWA-HRT-11-026, Federal Highway Administration, Washington, DC.

[20] Dynapac (2018), "Dynapac Instruction Manual Operating \& Maintenance", Karlskrona, Sweden.

[21] The website of Bomag worldwide, May 2018, https://www.bomag.com

[22] The website of Masalat, January 2019, http://www.masalta.com

[23] NTC (2017), "Production Information catalogue ", NTC STAVEBNÍ TECHNIKA, Czech Republic. 


\section{الضغط الناتج عن الامك فى حوائط التربة المسلحة بالمصنعات الجيوتقتية}

\section{الملخص العزبى}

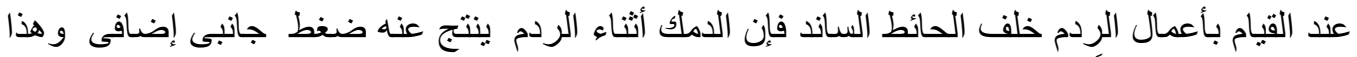

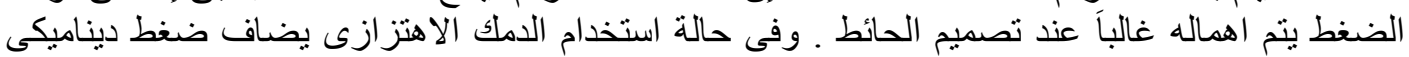

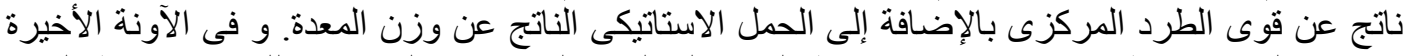

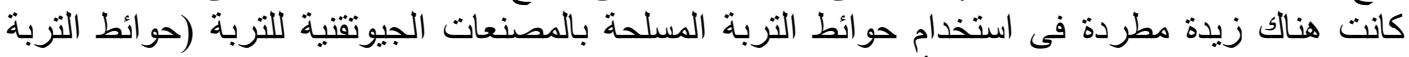

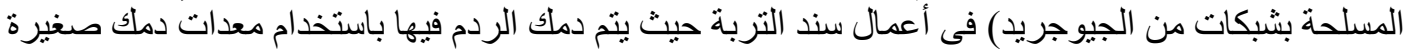

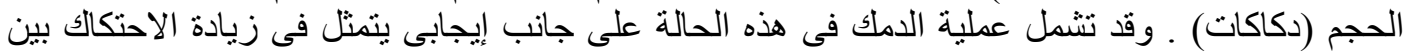

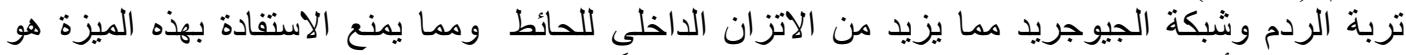

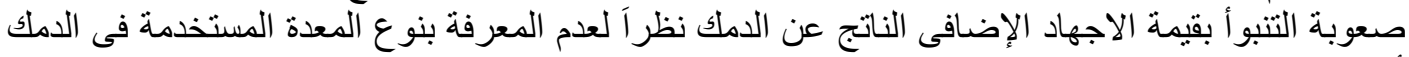

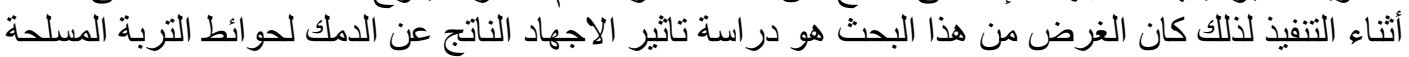

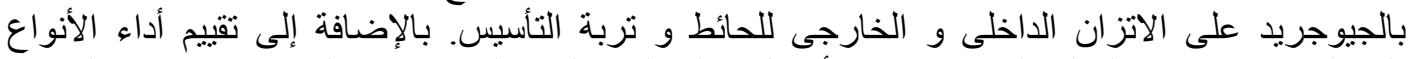

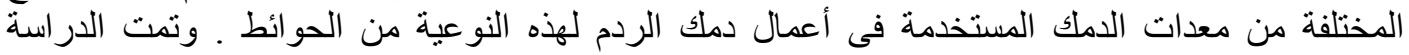

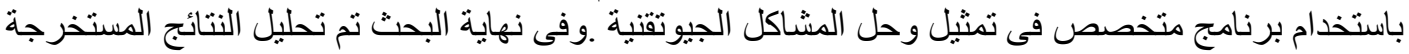
من البرنامج كما تم اعطاء توصيات بالخطوات الواجب اجب اتباعها عند تصميم وتنفيذ حوائط التربة المسلحة

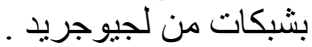

